\title{
A new bonded silica based on an amino acid derivative as a TLC stationary phase to solve nitrophenol structural isomerism and ibuprofen stereoisomerism
}

\author{
Mouhammad Abu Rasheed ${ }^{1 *}$ (D, Ahmad Alshaghel ${ }^{2}$ and Amir Alhaj Sakur ${ }^{1}$
}

\begin{abstract}
Background: Many amino acids and their derivatives have been used previously as chiral selectors in thin layer chromatography. Herein, we reported the synthesis, characterization, and chromatographic evaluation of a new modified stationary phase based on (S)-3-(aminomethyl)-5-methylhexanoic acid (also known as pregabalin) as an amino acid ligand bonded to the silica surface via triazine attachment.

Results: SC-2P (silica-cyanuric-2-pregabalin) is a bonded silica stationary phase prepared by direct binding of the pre-synthesized cyanuric-2-pregabalin organic ligand on the chlorinated silica surface. FT-IR and UV diffuse reflection spectroscopy (UV-DRS) were used to characterize the synthesized bonded phase, and the specific surface area was determined using the methylene blue Langmuir isotherm method to be $147.04 \mathrm{~m}^{2} / \mathrm{g}$. TLC plates were prepared from a slurry of this synthesized material with $2 \mathrm{mM}$ of $\mathrm{Cu}^{2+}$ as a selector additive, and the chromatographic characteristics of these plates were investigated to separate a ternary mixture of o-, $\mathrm{m}-$-, and $\mathrm{p}$ nitrophenol as structural isomers, and a racemic mixture of ( \pm )-ibuprofen as stereoisomers. Solvent systems of $\mathrm{n}$ hexane:dichloroethane:n-propanol (75:20:5, v/v/v) and Dichloroethane:acetonitrile (90:10, v/v) were selected as mobile phases for nitrophenol and ibuprofen mixtures, respectively. The successful separation was densitometrically confirmed, and retardation factors $\left(R_{\mathrm{f}}\right)$ were determined for $\mathrm{o}-, \mathrm{m}-$, and $\mathrm{p}$-nitrophenol at $320 \mathrm{~nm}$ to be $0.83,0.45$, and 0.28 , and for $\mathrm{R}(-)-$, $\mathrm{S}(+)$-ibuprofen at $220 \mathrm{~nm}$ to be 0.43 and 0.63 , respectively.
\end{abstract}

Conclusion: The synthesis, characterization, and chromatographic evaluation of SC-2P were reported in this article. SC-2P was used with copper ions to form in situ ligand exchange reagent (LER), which was successfully employed to solve an isomeric mixture of nitrophenol and a racemic mixture of ( \pm )-ibuprofen. The synthesized stationary phase showed high repeatability with minimum $R_{\mathrm{f}}$ shifts between batches.

Keywords: Thin layer chromatography, Stationary phase, Bonded silica, Ligand exchange reagent, Chiral selector, Enantioseparation

\footnotetext{
* Correspondence: mouhammed94a.b@hotmail.com

'Department of Food \& Analytical Chemistry, Faculty of Pharmacy, University

of Aleppo, Aleppo, Syria

Full list of author information is available at the end of the article
}

\section{Springer Open}

(c) The Author(s). 2020 Open Access This article is licensed under a Creative Commons Attribution 4.0 International License, which permits use, sharing, adaptation, distribution and reproduction in any medium or format, as long as you give appropriate credit to the original author(s) and the source, provide a link to the Creative Commons licence, and indicate if changes were made. The images or other third party material in this article are included in the article's Creative Commons licence, unless indicated otherwise in a credit line to the material. If material is not included in the article's Creative Commons licence and your intended use is not permitted by statutory regulation or exceeds the permitted use, you will need to obtain permission directly from the copyright holder. To view a copy of this licence, visit http://creativecommons.org/licenses/by/4.0/. 


\section{Background}

Thin layer chromatography (TLC) is well-known as simple, easy-to-prepare chromatographic technique which has been used as a selective, semi-quantitative method in wide applications. However, after the incorporation of densitometric measurements, this technique has become a reliable quantitative method [1]. In addition, some theories correlating the chromatographic characteristics of stationary phases between TLC and HPLC have been introduced [2], which makes it easier to evaluate new chromatographic phases more accurately using TLC.

Many of the amino acids [3-11] and their derivatives [8, $12,13]$ have been utilized previously as chemical ligands in TLC by impregnation [3-11, 13] or grafting [12], either as mono amino acid or even as purified protein [14]. These ligands were described in the literature as chiral selectors and used successfully in the enantioseparation of some moderately and highly polar racemic mixtures such as amino acids [13], non-steroidal anti-inflammatory drugs (NSAIDs) $[3,5,6,9,11]$, and $\beta$-blockers $[4,6-9]$.

In addition to the hydrophilic, dipole-dipole, and $\pi-\pi$ interactions, the separation mechanism which plays the major role in chiral recognition of these stationary phases is thought to be the ability of amino acid selector to constitute solute-selector complexes with the solute components [15]. These diastereomeric complexes have different configurations $(+,+/+,-$ or,$-+/-,-)$ and then different formation rates and stability constants leading to the separation of the racemic mixtures [8]. For this reason, an optically pure ligand is required. In many of the abovementioned research, copper ions were used as an additive to the chiral selector in order to improve the chiral recognition by forming (solute- $\mathrm{Cu}^{2+}$-selector) ternary complexes [8, 10-12]. In this case, the amino acid selector together with the copper ions used to modify the stationary phase are named as ligand exchange reagents (LERs).

Most of the amino acid-based chiral phases mentioned in the literature were prepared by impregnation, which consists of a physical unstable bond with the silica surface. That may significantly reduce the repeatability and reliability of chromatographic characteristics of these inhouse phases, and then affects the suitability of employing them in routine experiments. Besides, these phases were studied as chiral selectors to solve stereoisomers rather than structural isomers which are also considered as an analytical challenge.

In this article, (S)-3-(aminomethyl)-5-methylhexanoic acid, which is known as pregabalin to treat neuropathic pain [16], was utilized as a new amino acid chiral selector to modify the silica surface and was covalently bonded to silica gel via triazine attachment.

Three techniques were conducted to characterize the synthesized phase. The first one is FT-IR, which was used as a primary characterizing method. The second is
UV diffuse reflection spectroscopy (UV-DRS), which was poorly mentioned in the literature as a characterizing technique [17] but showed high repeatability to be used as a complementary method. Specific surface area (SSA) was also determined via Langmuir adsorption isotherm using methylene blue (MB) molecules as an adsorbate.

This new bonded phase was used as a slurry with copper ions to prepare TLC plates, which were evaluated to solve the two types of isomerism. Nitrophenol isomers and a racemic mixture of $( \pm)$-ibuprofen were selected as model structural and stereoisomeric mixtures, respectively.

\section{Methods \\ Materials}

Silica Gel 60 for TLC and acetonitrile gradient grade for liquid chromatography were supplied from Merck, Germany. Thionyl chloride (97\%), cyanuric chloride (97\%), acetone (98\%), methylene blue. $\mathrm{XH}_{2} \mathrm{O}(X=2-3)$, and (S)-(+)-ibuprofen (99\%) were supplied from SigmaAldrich, Germany. Sodium hydroxide pellets (98\%) and sodium hydrogen carbonate (99\%) from Rectapur Prolabo, EEC. 1,4-Dioxane (99.5\%), toluene (99.8\%), 1,2-dichloroethane (DCE) (99.5\%), dichloromethane (DCM) (99\%), and hydrochloric acid (37\%) were supplied from Scharlab S.L., Spain. n-Hexane HPS grade for HPLC (95\%) and n-propanol (99\%) were from Surechem products LTD., England. Copper(II) sulfate pentahydrate (99\%) was supplied by alfa-Aesar, USA. 2-nitrophenol, 3-nitrophenol, 4-nitrophenol, and PolyVinyl Alcohol (PVA) 98\% were from Fisher Scientific, USA. ( \pm )-Ibuprofen and pregabalin were purchased from AbaChemScene, USA.

\section{Apparatus}

NEY M-525 Series 2 oven (Yucaipa CA) was used for drying processes. FT-IR spectra were recorded on Jasco FT/ IR-4200. Shimadzu "dual wavelength flying spot scanning" densitometer CS-9301 PC (program version 2.00) was used for UV-DRS scanning and densitometric analysis of the plates after separation, and "ASCII translate" function in the software package was used to export the observed data to Microsoft Office Excel for further processings and calculations. T70 UV/VIS Spectrometer (PG instruments) was used for spectrophotometric measurements to calculate the specific surface area. Camag TLC plate coater (hand-operated) was used to prepare TLC plates. Hamilton 1- $\mu \mathrm{L}$ micro-syringe (Switzerland) was used to apply samples on TLC plates. Wheaton Hellendahl Staining Dish $(7.5 \times 2.5 \times 7.5 \mathrm{~cm})$ was used as a TLC developing chamber. Structures of the molecules were drawn using MarvinSketch, version 18.18 (ChemAxon LTD.). Microsoft Office Excel (Version 2016) was used for UV- 
DRS data processing and Kubelka-Munk function calculations.

\section{Synthesis of cyanuric-2-pregabalin (C-2P)}

The synthesis of C-2P $\left(M_{\mathrm{w}}=411.503 \mathrm{~g} / \mathrm{mol}\right)$ was performed according to a method modified from that of Fang et al. [18]. In a round bottom flask, $1.03 \mathrm{~g}(6.5$ mmol) of pregabalin, $0.48 \mathrm{~g}$ of $\mathrm{NaOH}$, and $0.7 \mathrm{~g}$ of sodium hydrogen carbonate were dissolved in $75 \mathrm{~mL}$ of distilled water previously heated to $50{ }^{\circ} \mathrm{C}$, then $0.6 \mathrm{~g}(3.2$ $\mathrm{mmol}$ ) of cyanuric chloride dissolved in $15 \mathrm{~mL}$ of 1,4 dioxane was added to the solution and stirred for $10 \mathrm{~min}$ at room temperature. After that, it is heated under reflux at $70{ }^{\circ} \mathrm{C}$ for $3 \mathrm{~h}$. Then, the mixture was cooled, and $\mathrm{HCl}$ (20\%) was added to adjust $\mathrm{pH}$ at 3 . A light pink precipitate was obtained. The solid was filtered and washed with water and ethanol, and then dried at $70{ }^{\circ} \mathrm{C}$ overnight to obtain the organic ligand (C-2P) (Fig. 1).

\section{Synthesis of chlorinated silica $\mathrm{SiO}_{2}-\mathrm{cl}$}

Silica gel was chlorinated using thionyl chloride $\left(\mathrm{SOCl}_{2}\right)$ according to Maity et al.'s [19] modified method. Silica gel powder was heated at $200{ }^{\circ} \mathrm{C}$ under vacuum for $2 \mathrm{~h}$ before being used for the synthesis. Ten grams of $\mathrm{SOCl}_{2}$ was added dropwise under stirring to a suspension of 10 g of silica gel in $50 \mathrm{~mL}$ of DCM at room temperature and stirred vigorously for $2 \mathrm{~h}$, then filtered and washed three times with DCM. The synthesized material was dried under vacuum at room temperature overnight to yield chlorinated silica $\mathrm{SiO}_{2}-\mathrm{Cl}$.

\section{Synthesis of SC-2P stationary phase}

In a round bottom flask, $10 \mathrm{~g}$ of chlorinated silica $\left(\mathrm{SiO}_{2}-\right.$ $\mathrm{Cl}$ ) was suspended in $50 \mathrm{~mL}$ of toluene. Two grams of the pre-synthesized organic ligand $(\mathrm{C}-2 \mathrm{P})$ and $0.3 \mathrm{~g}$ of potassium hydroxide were dissolved in $30 \mathrm{~mL}$ of acetone and then added dropwise to the silica suspension and refluxed at $70^{\circ} \mathrm{C}$ for $24 \mathrm{~h}$ under nitrogen atmosphere. The solid was then filtered and washed several times with water and acetone, and dried at $100{ }^{\circ} \mathrm{C}$ for $6 \mathrm{~h}$ (Fig. 2).

\section{Characterization of SC-2P}

Three techniques were employed for SC-2P characterization. FT-IR spectra were recorded for the dried samples of $\mathrm{C}-2 \mathrm{P}$ and $\mathrm{SC}-2 \mathrm{P}$ using $\mathrm{KBr}$ discs containing $1 \mathrm{mg}$ of the sample. UV-DRS spectra were recorded using Shimadzu densitometer for samples of chlorinated silica $\left(\mathrm{SiO}_{2}-\mathrm{Cl}\right)$ and bonded silica (SC-2P), by spreading a small amount of sample on a glass plate and putting it into the instrument. The relevant Kubelka-Munk function patterns were calculated according to Eq. 1 and drawn using Microsoft Office Excel.

$$
\mathrm{F}(\mathrm{R})=\frac{K}{S}=\frac{(R-1)^{2}}{2 R}
$$

Equation 1 represents the Kubelka-Munk equation, where $\mathrm{F}(\mathrm{R})$ is the Kubelka-Munk function, $K$ is the absorption coefficient $\left[\mathrm{Cm}^{-1}\right], S$ is the scattering coefficient $\left[\mathrm{Cm}^{-1}\right]$, and $R$ is the diffuse reflectance [20].

The specific surface area (SSA) was determined for the synthesized SC-2P stationary phase using Langmuir adsorption isotherm of methylene blue $(\mathrm{MB})$ as prescribed by Itodo et al. [21]. Equations 2 and 3 respectively represent the linear Langmuir equation type 1 and SSA equation. These equations were used for SSA determination as follows.

$$
\begin{aligned}
\frac{C_{\mathrm{eq}}}{q_{\mathrm{eq}}} & =\left(\frac{1}{q_{\mathrm{m}}}\right) C_{\mathrm{eq}}+\frac{1}{K q_{\mathrm{m}}} \\
\mathrm{SSA} & =\frac{\mathrm{q}_{\mathrm{m}} \times N \times A}{1000 \times M_{\mathrm{w}}}
\end{aligned}
$$

where $C_{\text {eq }}(\mathrm{mg} / \mathrm{L})$ is the equilibrium concentration of $\mathrm{MB} ; q_{\mathrm{eq}}$ and $q_{\mathrm{m}}(\mathrm{mg} / \mathrm{g})$ are the amount of $\mathrm{MB}$ adsorbed by $1 \mathrm{~g}$ of the stationary phase at the equilibrium and when a full monolayer of $\mathrm{MB}$ is formed, respectively; $K$ is the equation constant; $N$ is Avogadro's number

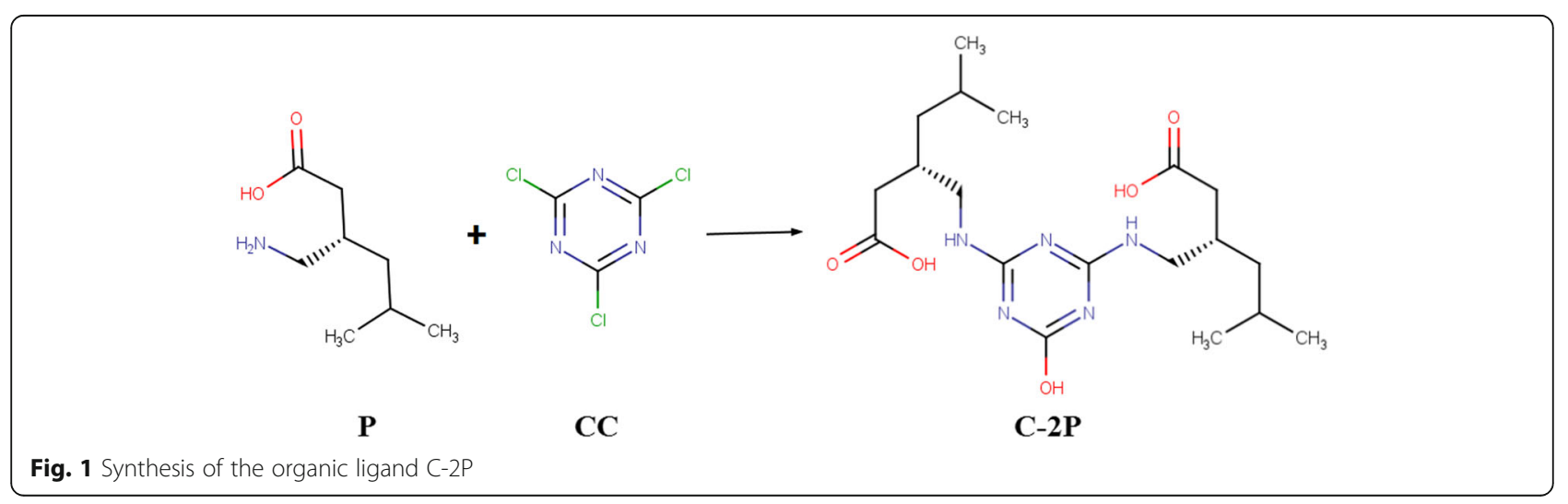




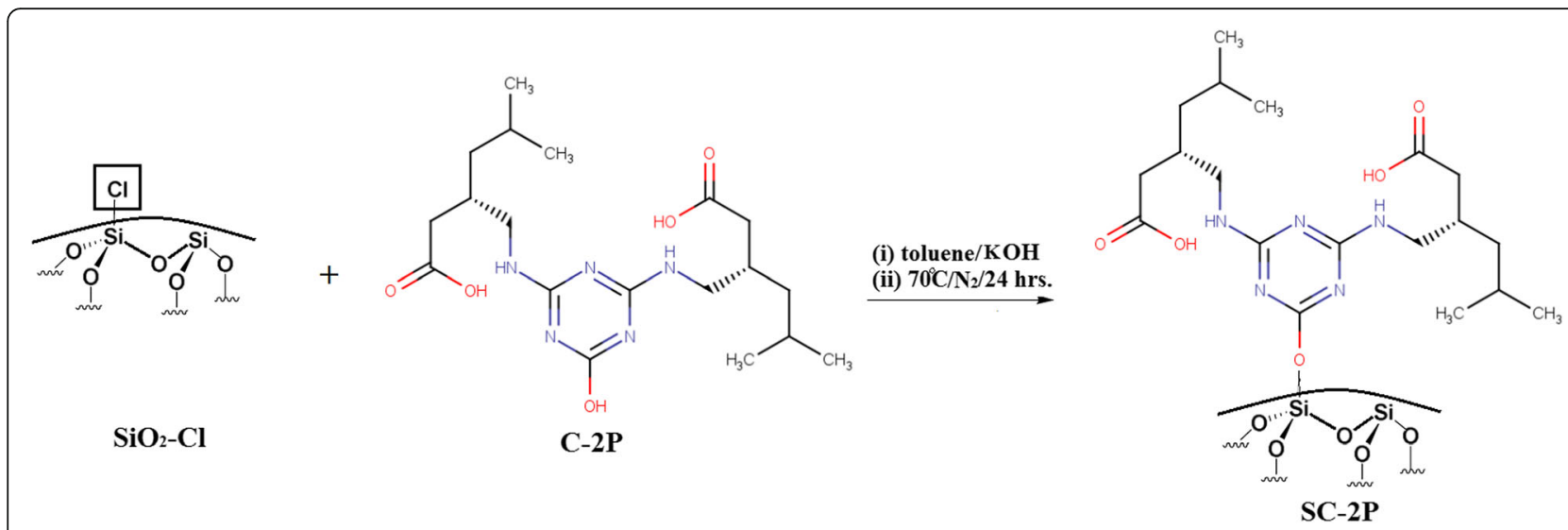

Fig. 2 Synthesis of the bonded silica SC-2P
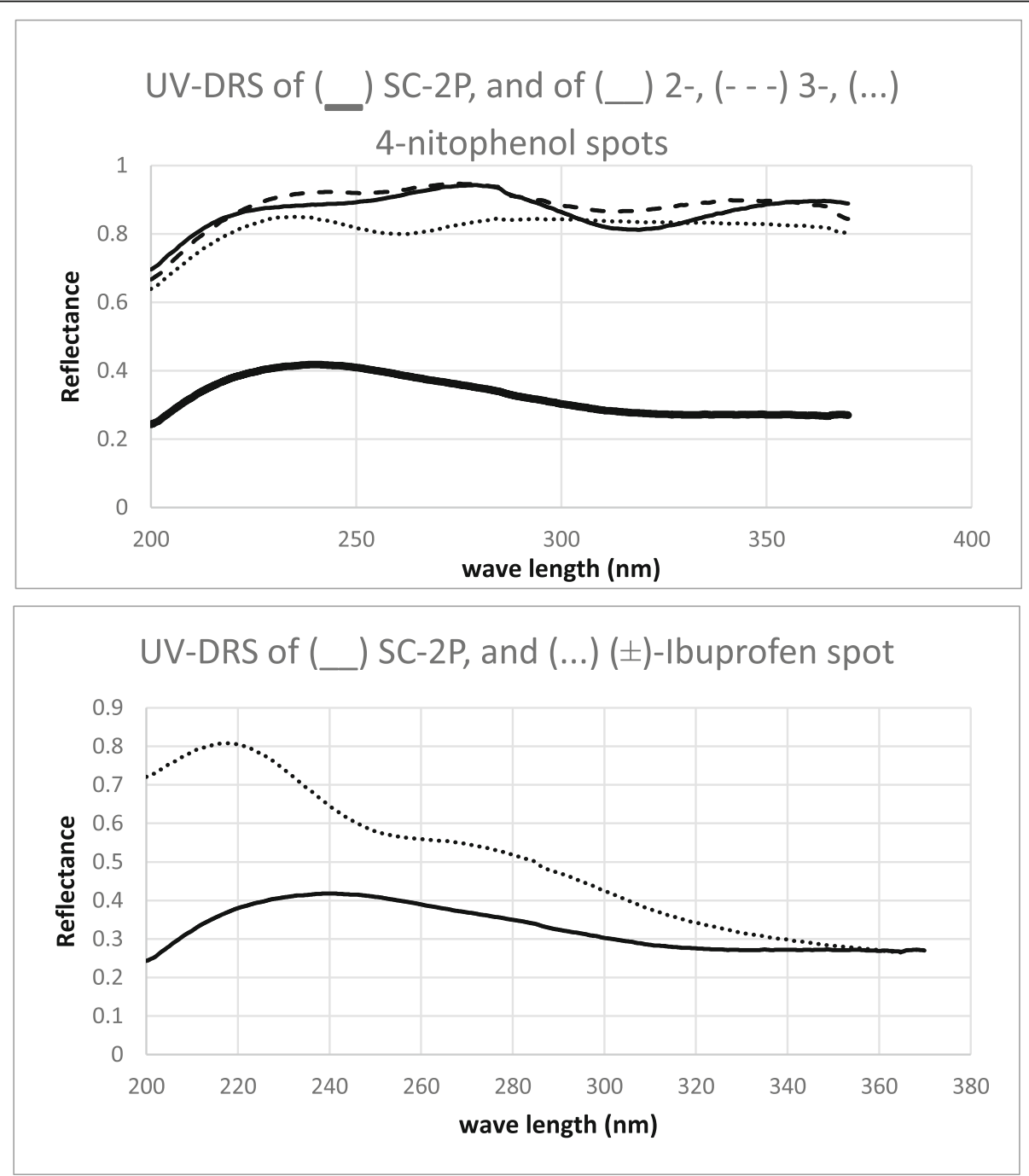

Fig. 3 UV-DRS spectra of the prepared TLC plates and for the spots 
$\left(6.019 \times 10^{23} \mathrm{~mol}^{-1}\right) ; A$ is the surface area occupied by one molecule of MB $\left(197.2 \AA^{2}\right)$; and $M_{\mathrm{w}}(\mathrm{g} / \mathrm{mol})$ is the molecular weight of MB.

Several concentrations of methylene blue in distilled water were prepared in the range of $40-80 \mathrm{mg} / \mathrm{L}$. Twenty-five milligrams of SC-2P was suspended in 10 $\mathrm{mL}$ of each of the previous solutions with frequent shaking for $6 \mathrm{~h}$. To reach the equilibrium state, $C_{\text {eq }}$ and $q_{\text {eq }}$ values were spectrophotometrically determined at 665 $\mathrm{nm}$. The linear equation (Eq. 2) was drawn according to the observed data (Additional file 1). The other three types of Langmuir equation were also used (Additional file 1) to make comparisons.

\section{TLC plates preparation and chromatographic conditions} Glass slides $(7.5 \times 2.5 \mathrm{~cm})$ were used to prepare TLC plates of $100-\mu \mathrm{m}$ thickness using Camag TLC plate coater. Aqueous solution of $2 \mathrm{mM}$ of copper sulfate pentahydrate was prepared. One gram of SC-2P was suspended in $10 \mathrm{~mL}$ of $\mathrm{Cu}^{2+}$ :methanol $(1: 2, \mathrm{v} / \mathrm{v})$ containing polyvinyl alcohol (PVA) $0.2 \%$ as a binder. TLC plates were dried at room temperature and then at $100^{\circ} \mathrm{C}$ for $3 \mathrm{~h}$. The same protocol was applied to prepare TLC plates of SC-2P without using copper sulfate solution to compare the chromatographic characteristics. UV-DRS spectra were recorded for the prepared plates and for the spots (Fig. 3), in order to determine suitable wavelengths for the densitometric measurements, in which wavelengths of $320 \mathrm{~nm}$ and $220 \mathrm{~nm}$ were selected for nitrophenol and ibuprofen mixtures, respectively.

A ternary mixture of $5 \mathrm{mg} / \mathrm{mL}$ of $\mathrm{o}-, \mathrm{m}^{-}$, and $\mathrm{p}$ nitrophenol in methanol was prepared. Control solutions of the three components were also prepared at the same concentration. One microliter-spots of these solutions were applied to the prepared plates and developed using different mobile phase systems to determine the one that gives acceptable separation (Table 1). The mobile phases

Table 1 Retardation factors of p-, m-, and o-nitrophenol, and

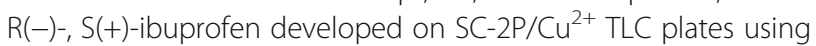
different mobile phase systems (MPs)

\begin{tabular}{|c|c|c|c|c|c|}
\hline Nitrophenols & MP-1 & MP-2 & MP-3 & MP-4 & MP-5 \\
\hline$p$-isomer $R_{\mathrm{f}}$ & 0.09 & 0.12 & 0.56 & 0.28 & 0.67 \\
\hline$m$-isomer $R_{\mathrm{f}}$ & 0.19 & 0.22 & 0.86 & 0.45 & 0.79 \\
\hline o-isomer $R_{\mathrm{f}}$ & 0.85 & 0.91 & 0.89 & 0.83 & 0.87 \\
\hline ( \pm )-Ibuprofen & MP-6 & MP-7 & MP-8 & MP-9 & \\
\hline $\mathrm{R}(-)$-ibuprofen $R_{\mathrm{f}}$ & 0.79 & 0.59 & 0.43 & 0.39 & \\
\hline $\mathrm{S}(+)$-ibuprofen $R_{\mathrm{f}}$ & 0.82 & 0.67 & 0.63 & 0.54 & \\
\hline
\end{tabular}

MP-1 n-hexane:DCE (50:50), MP-2 n-hexane:DCE (75:25), MP-3 n-hexane:DCE:2propanol (75:20:5), MP-4 n-hexane:DCE:n-propanol (75:20:5), MP-5 nhexane:DCE:n-propanol (75:15:10), MP-6 DCE:Acetonitrile (70:30), MP-7 DCE:Acetonitrile (80:20), MP-8 DCE:Acetonitrile (90:10), MP-9 DCE:Acetonitrile (95:5) were let to develop for about $5 \mathrm{~cm}$ at room temperature; then, the plates were dried and densitometric measurements were applied to determine the retardation factors $\left(R_{\mathrm{f}}\right)$ (linear, reflection mode). These measurements were used to determine the separation factors $\alpha$. Three independent experiments were conducted on plates prepared from different batches of $\mathrm{SC}-2 \mathrm{P}$, and shifts in $R_{\mathrm{f}}$ values were observed.

The same protocol was applied to separate a $5 \mathrm{mg} / \mathrm{mL}$ solution of $( \pm)$-ibuprofen, but with different mobile phase systems trialed (Table 1).

\section{Results}

The resulting material was a pale white precipitate. FTIR spectra were observed for the synthesized organic ligand $(\mathrm{C}-2 \mathrm{P})$ and the grafted silica $(\mathrm{SC}-2 \mathrm{P})$, and are shown in Fig. 4.

UV-DRS spectra for samples of chlorinated silica $\left(\mathrm{SiO}_{2}-\mathrm{Cl}\right)$ and bonded silica (SC-2P) along with the calculated Kubelka-Munk function are shown in Fig. 5 a and $b$, respectively.

In order to calculate the specific surface area, $q_{\mathrm{m}}$ value was determined as the reciprocal of the slope of Eq. 2 linear plot (Additional file 1). The calculated $q_{\mathrm{m}}$ value was $44.64 \mathrm{mg} / \mathrm{g}$. This value was applied to the SSA equation (Eq. 3). By comparing the physical characteristics of the methylene blue powder used in this work with the different types of methylene blue hydrate determined by Rager et al. [22], our methylene blue is the Type-B hydrate with a mean molecular weight of $\sim 360.35 \mathrm{~g} / \mathrm{mol}$. The calculated specific surface area of the synthesized SC-2P stationary phase is $147.04 \mathrm{~m}^{2} / \mathrm{g}$. By employing the other three types of Langmuir equation, quite similar results were obtained, as SSA values were in the range of $142.07-147.09 \mathrm{~m}^{2} / \mathrm{g}$.

Mixture solutions of nitrophenol isomers and ( \pm )-ibuprofen were applied to the prepared plates of SC-2P/ $\mathrm{Cu}^{2+}$ and developed for $5 \mathrm{~cm}$. Table 1 shows the results of using different mobile phase systems on $R_{\mathrm{f}}$ values for the two mixtures in which a system of n-hexane:DCE:npropanol (75:20:5, v/v/v) and DCE:acetonitrile (90:10, v/ v) were chosen as optimized mobile phases to obtain acceptable separation for nitrophenol and ibuprofen mixtures, respectively (Fig. 6). TLC plates prepared from SC-2P without copper additive were also used to develop the two mixtures' solutions using the predetermined optimized mobile phases for comparison (Fig. 7).

\section{Discussion}

SC-2P-bonded phase was synthesized via simple solvothermal condensation of the pre-synthesized pregabalinbased substituted triazine ligand with the chlorinated silica. Its probable structure is shown in Fig. 2. 

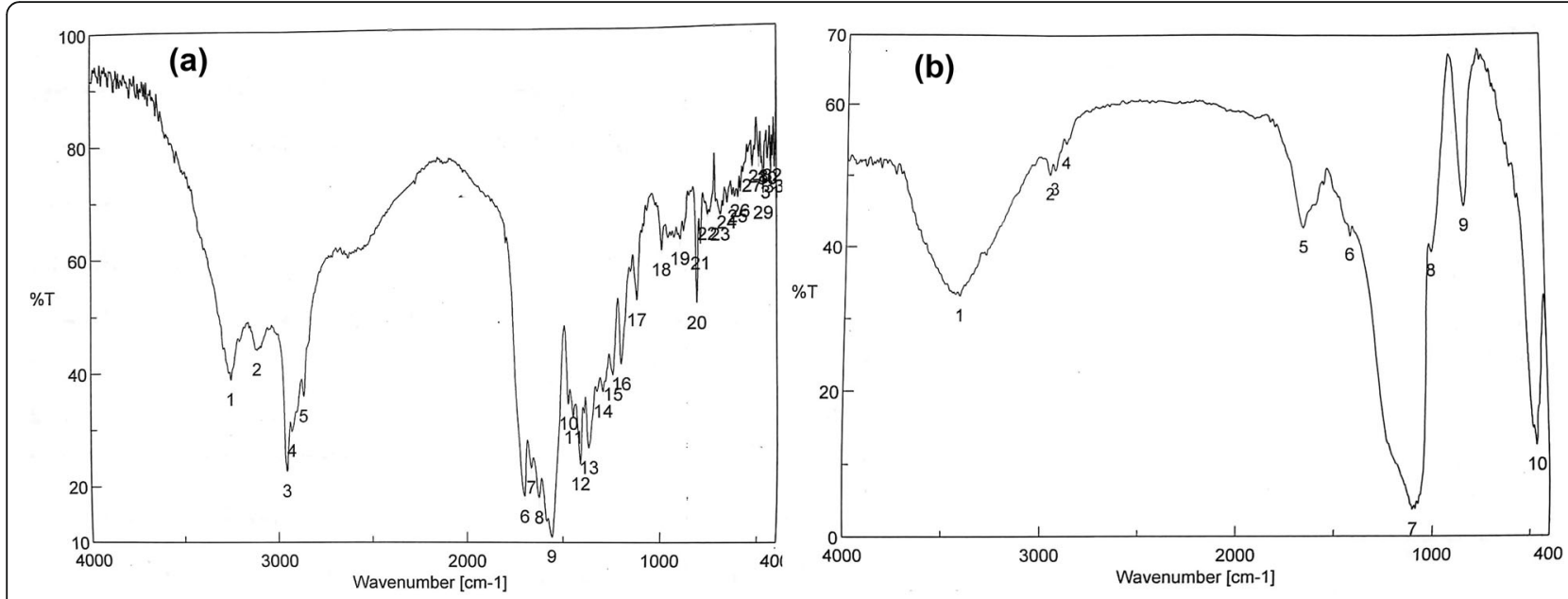

Fig. 4 FTIR spectra of $\mathbf{a}$ organic ligand $C-2 P$ and $\mathbf{b}$ grafted silica SC-2P
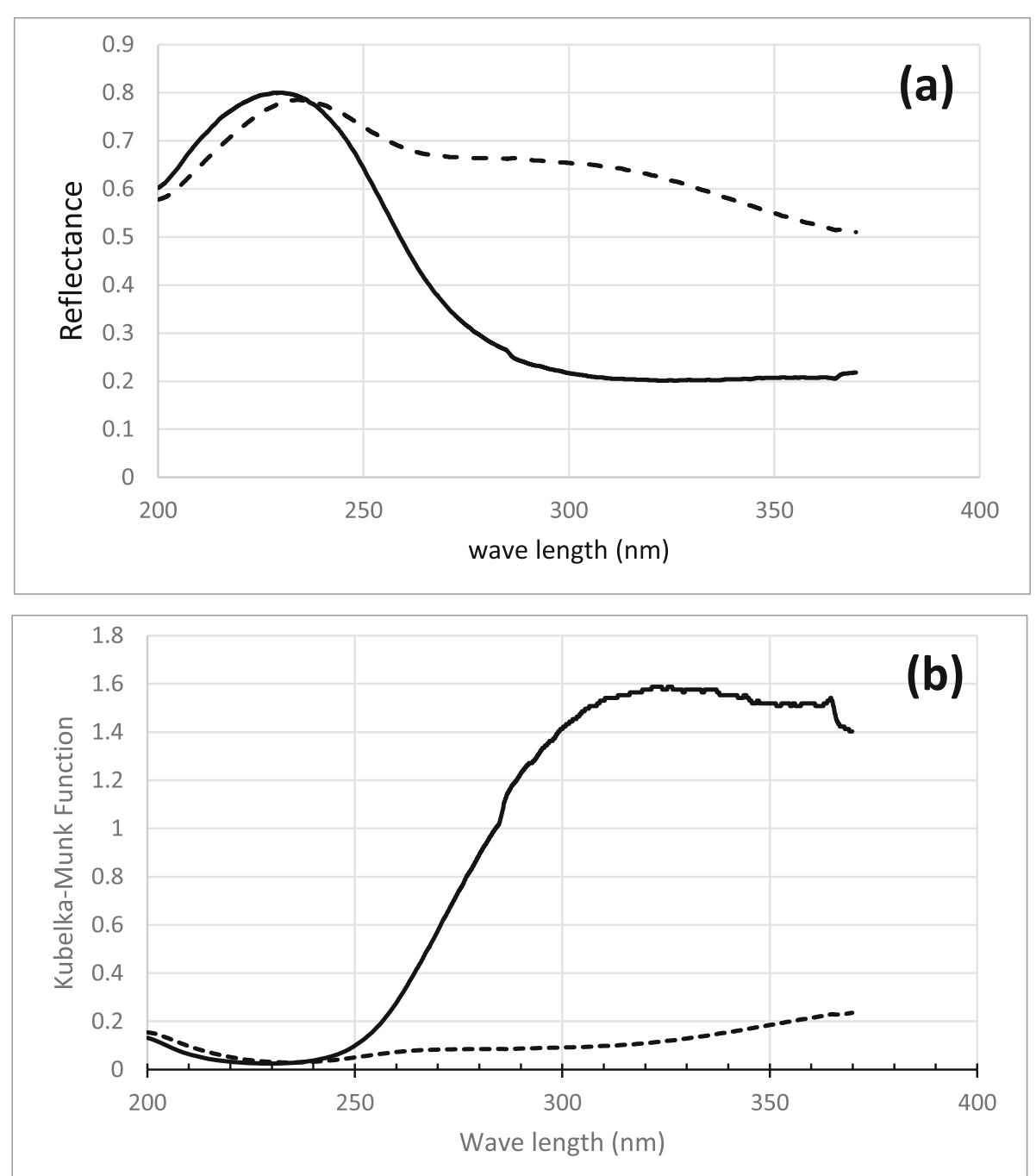

Fig. 5 a UV diffuse reflection spectra and $\mathbf{b}$ Kubelka-Munk function F(R) patterns* of chlorinated silica (dotted lines) and SC-2P bonded silica (solid lines) 

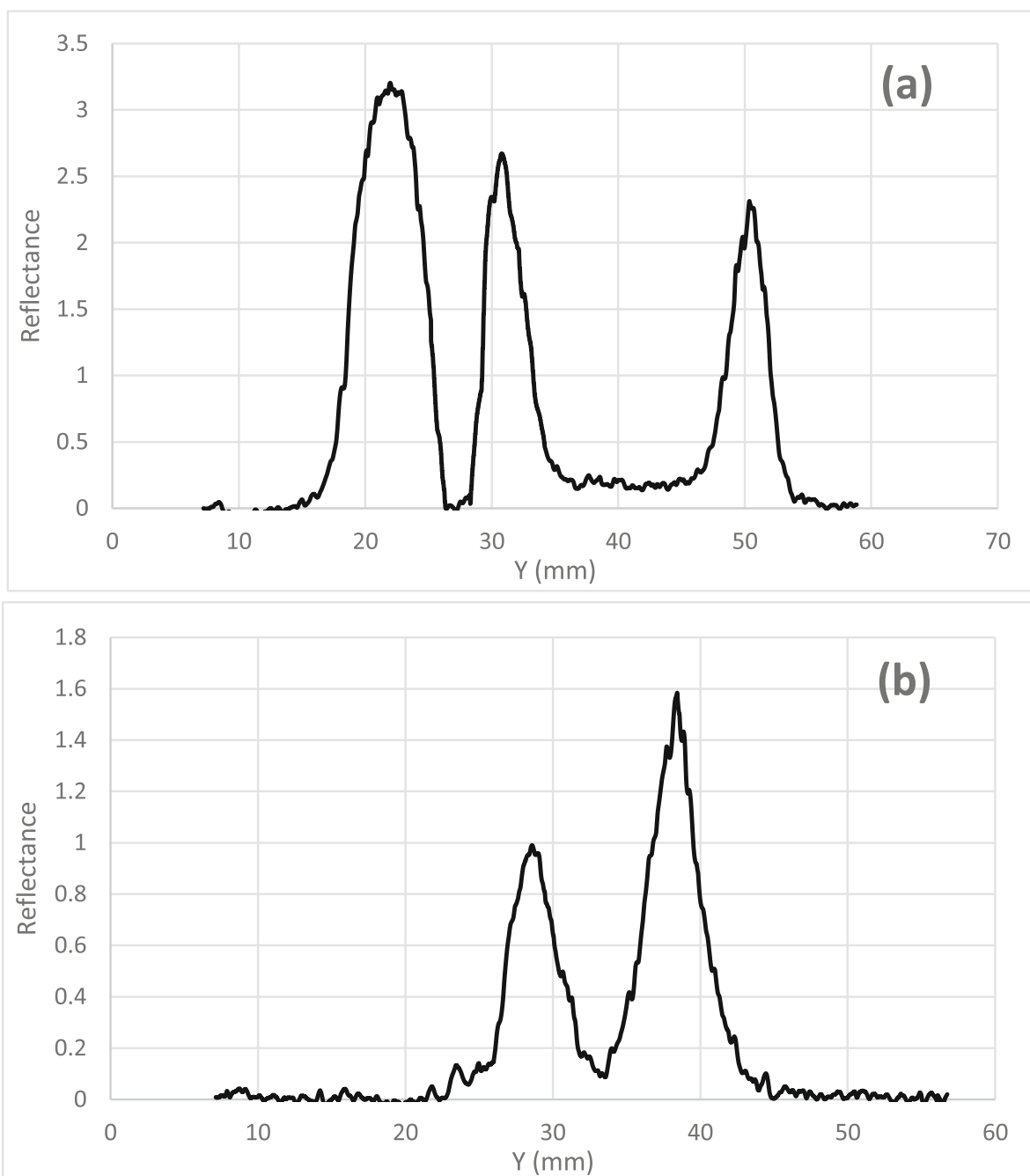

Fig. 6 Densitograms of the separated mixtures on SC-2P/Cu ${ }^{2+}$ TLC plates. Spots mentioned from left to right as a p-, m-, and o-nitrophenol using n-hexane:DCE:n-propanol (75:20:5, v/v/v) as mobile phase system and $\mathbf{b}$ R(-)-, S(+)-ibuprofen using DCE:acetonitrile (90:10, v/v) as mobile phase system

The organic ligand and the resultant stationary phase showed low thermal stability when temperatures higher than $150^{\circ} \mathrm{C}$ were used during the synthesis or the drying steps; thus, a synthesis temperature of no more than $70{ }^{\circ} \mathrm{C}$ and a drying temperature of no more than $100^{\circ} \mathrm{C}$ were suitable. This low thermal stability was observed as these materials were turning into brown color upon heating, which suspects that inter-molecular Maillard reactions are taking place [23]. Conversely, SC-2P stationary phase showed good chemical stability when acidic $(\mathrm{pH}=3)$ or basic $(\mathrm{pH}=9)$ solutions were used as mobile phases, as no changes were observed in its FT-IR or UVDRS spectra.

\section{Characterization of SC-2P}

According to the FT-IR measurements (Fig. 4), the bands observed in the range of $3000-2800 \mathrm{~cm}^{-1}$ and $\sim 1600 \mathrm{~cm}^{-1}$ in both samples are for $\mathrm{C}-\mathrm{H}$ and $\mathrm{C}=\mathrm{O} / \mathrm{C}=\mathrm{N}$ stretching, respectively. The broad band in the range of $3500-2500 \mathrm{~cm}^{-1}$ which refers to the $-\mathrm{COOH}$ group dimers in $\mathrm{C}-2 \mathrm{P}$ was not observed in $\mathrm{SC}-2 \mathrm{P}$; this could be due to the steric effects that prevent the formation of inter-molecular hydrogen bonds in the bonded silica. The band at $3417 \mathrm{~cm}^{-1}$ in SC-2P could be for $\mathrm{O}-\mathrm{H} / \mathrm{N}-\mathrm{H}$ or free $\mathrm{SiO}-\mathrm{H}$ stretching [24]. The two strong bands at $1100 \mathrm{~cm}^{-1}$ and $463 \mathrm{~cm}^{-1}$ in SC-2P refer to the stretching of $\mathrm{Si}-\mathrm{O}-\mathrm{Si}$ and $\mathrm{Si}-\mathrm{O}$ rocking, respectively, and the strong band at $972 \mathrm{~cm}^{-1}$ can be assigned to $\mathrm{Si}-\mathrm{O}-\mathrm{Ph}$ stretching. It is unlikely that the organic ligand binds to the silica surface via $\mathrm{Si}-\mathrm{N}$ or $\mathrm{Si}-\mathrm{O}-\mathrm{CO}$ bonds as their stretching bands in the ranges of $1550-1540 \mathrm{~cm}^{-1}$ and $1770-1725 \mathrm{~cm}^{-1}$, respectively, were not observed [25].

UV-DRS spectra along with the Kubelka-Munk function patterns (Fig. 5) were used as a complementary characterizing method for the synthesized bonded phase. According to Kubelka-Munk equation (Eq. 1), the 

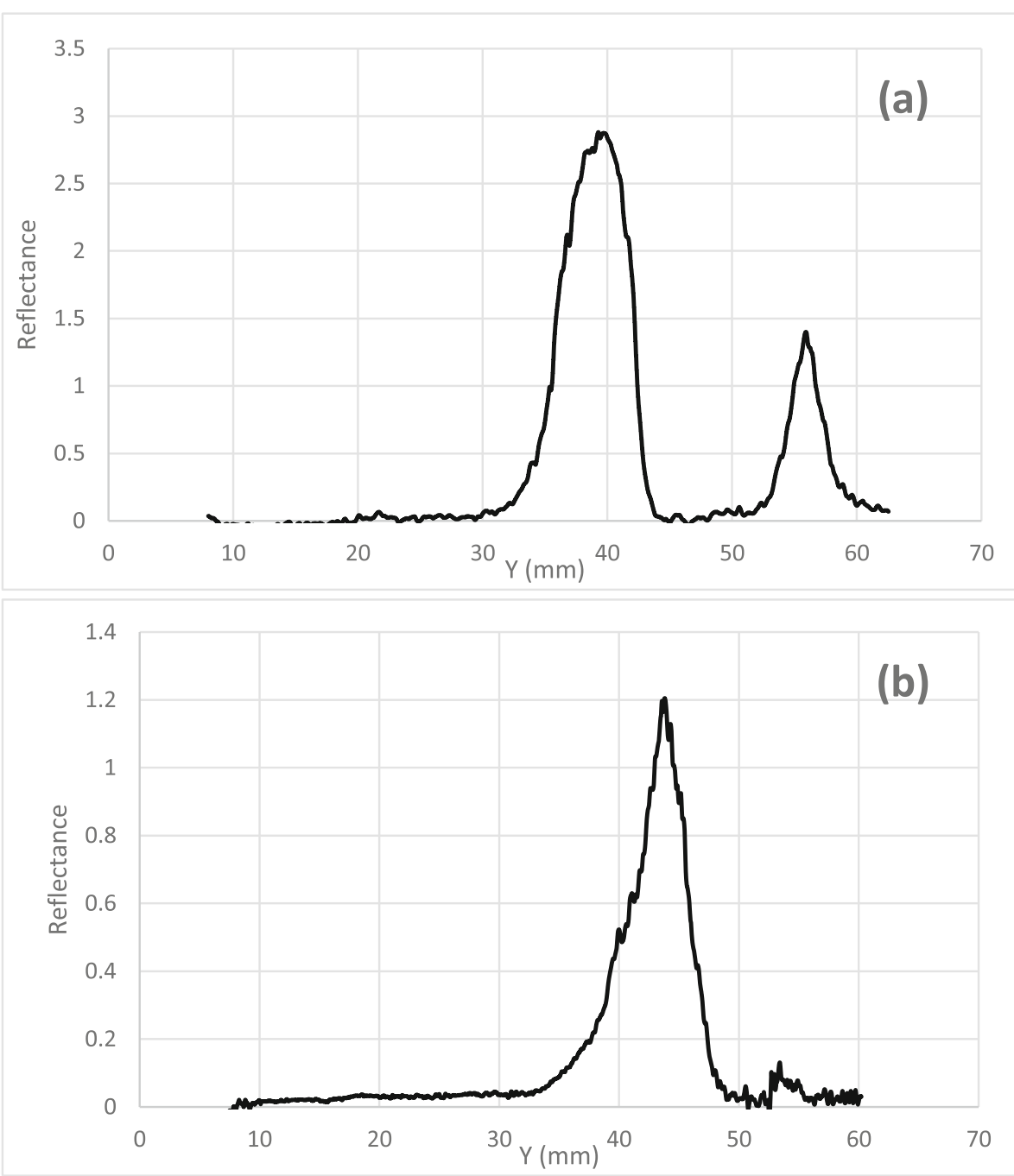

Fig. 7 Densitograms of a nitrophenol and $\mathbf{b}( \pm)$-ibuprofen mixtures developed on SC-2P TLC plates without copper additive

increase in $F(R)$ values observed for the bonded phase in comparison to the chlorinated silica could be due to two reasons. Firstly, the presence of the organic moiety in the bonded phase leads to a significant increase in $K$ value, and secondly, the decrease in the specific surface area which usually accompanies the grafting processes can cause a decline in $S$ value. This pattern was not observed at wave lengths below $250 \mathrm{~nm}$. This could be due to the high absorptivity of silica surface for the two samples and the low absorptivity of the organic ligand in the bonded phase sample in this range. Although the Kubelka-Munk theory of diffuse reflection has some limitations, which makes it poorly employed as a characterizing technique in the UV range, it was easily conducted and showed high repeatability between different batches of both chlorinated and bonded silica samples.

The calculated specific surface area determined in this study confirms the favorable characteristics of the synthesized SC-2P to be used as a TLC stationary phase. In addition, the applied Langmuir isotherm method showed good repeatability and flexible probability for the different types of Langmuir equation to be used.

\section{Chromatographic evaluation of SC-2P}

The properties of SC-2P as a TLC stationary phase were studied in the presence of copper ions to form ligand exchange reagent (LER). Two isomeric mixtures were used to evaluate the chromatographic characteristics of the stationary phase and its ability to solve different types of isomerism. A mixture of nitrophenol isomers was selected as a model of structural isomerism. This mixture was successfully separated on $\mathrm{SC}-2 \mathrm{P} / \mathrm{Cu}^{2+} \mathrm{TLC}$ plates using a mobile phase of n-hexane:DCE:n-propanol (75: 20:5, v/v/v) (Fig. 6a), as three separated peaks were determined in the densitogram which were compared to those in the densitograms of control solutions. $R_{\mathrm{f}}$ values 
were densitometrically determined and were $0.83,0.45$, and 0.28 for $\mathrm{o}^{-}, \mathrm{m}-$, and $\mathrm{p}$-nitrophenol, respectively. The successful separation was confirmed as $\alpha$-values were 6.09 for o-, m-nitrophenol, and 2.15 for m-, pnitrophenol.

Likewise, a racemic mixture of ( \pm )-ibuprofen was employed to study the chiral selectivity of $\mathrm{SC}-2 \mathrm{P} / \mathrm{Cu}^{2+}$ stationary phase. Depending on the densitometric measurements of the developed spot using DCE:acetonitrile $(90: 10, v / v)$ as a mobile phase (Fig. $6 \mathrm{~b})$, this mixture was also separated with $R_{\mathrm{f}}$ values of 0.43 , and 0.63 for (-)-, $(+)$-ibuprofen, respectively. The calculated $\alpha$-value was 2.24 .

$R_{\mathrm{f}}$ values changed within the range of \pm 0.02 between plates prepared from different batches of the synthesized stationary phase, which is considered neglected and could be due to shifts in the mobile phase fractions and room temperature changes.

The same mixtures were developed on TLC plates prepared from SC-2P slurry without copper ions addition, and the same mobile phase systems were used. The resulted densitograms are shown in Fig. 7, which confirm the advantage of using copper additive to enhance the selectivity of SC-2P, as there was no resolution observed between $\mathrm{m}$ - and $\mathrm{p}$-nitrophenol in the first structural isomeric mixture, and, similarly, the racemic mixture of $( \pm$ )-ibuprofen gave one spot.

According to the literature, the selectivity of stationary phases containing LERs is mainly owing to the ability of these reagents to form (solute- $\mathrm{Cu}^{2+}$-ligand) ternary complexes. These complexes are of different stability constants due to the configuration differences and the steric effects. Our results were consistent with this proposed mechanism. For the structural isomers of nitrophenol, the steric effect of the ortho- $\mathrm{NO}_{2}$ group in o-nitrophenol led to a decrease in the capability of the $-\mathrm{OH}$ group of o-isomer to form ternary complexes with LERs, in addition to the simple hydrogen bonds with the free $-\mathrm{COOH}$ groups on SC-2P. This steric effect declines for the other two isomers which showed a closer affinity to the stationary phase, with the para-isomer exhibiting the highest capability to interfere with the surface, as it corresponded to the lowest $R_{\mathrm{f}}$ value.

The successful separation of $( \pm)$-ibuprofen stereoisomers on $\mathrm{SC}-2 \mathrm{P} / \mathrm{Cu}^{2+}$ can be similarly illustrated, as the different spatial arrangements of atoms in the solute components will lead to the formation of diastereomeric complexes of different configurations (S-ibuprofen-$\mathrm{Cu}^{2+}--\mathrm{S}$-ligand, and $\mathrm{R}$-ibuprofen-- $\mathrm{Cu}^{2+}--\mathrm{S}$-ligand). The latter configuration is more stable than the former, which explains the difference in the observed $R_{\mathrm{f}}$.

Moreover, both mixture components and SC-2P stationary phase are of moderate polarity and consist of a hydrophobic aromatic ring with polar hydroxyl or carboxylic acid group. Thus, other mechanisms such as $\pi-\pi$ interactions, and H-bond formation might have a role in the separation process.

The separation of nitrophenol isomers was previously reported using RP-HPLC methods [26, 27]. However, our work is the first to describe a successful separation of the ternary mixture of nitrophenols using LER-based TLC plates.

The use of LER-based stationary phases provided good enantioselectivity to solve some racemic mixtures of NSAIDs-like drugs such as Bupropion [10] and Baclofen [11]. On the other hand, the reported work that separated a racemic mixture of ibuprofen using amino acids as chiral selectors needed two-dimensional development to give an acceptable resolution [3]. $\mathrm{SC}-2 \mathrm{P} / \mathrm{Cu}^{2+}$ stationary phase provides successful separation of $( \pm$ )-ibuprofen using LER-based stationary phase with simple onedimensional development.

Besides, unlike most of the other previous phases which were prepared by impregnation with the chiral selector, SC-2P is based on a distinct structure of chemically stable triazine linker that binds two molecules of pregabalin with the same optical configuration to the silica surface. The stability of selector on the stationary phase could enable the employing of $\mathrm{SC}-2 \mathrm{P}$ in column isomeric separations using HPLC.

Therefore, the synthesized $\mathrm{SC}-2 \mathrm{P} / \mathrm{Cu}^{2+}$ stationary phase provides a good alternative to the previously mentioned amino acid based chiral phases, as it has the advantage of being able to solve both structural and stereo-isomerism with good selectivity. However, the use of copper ions as an additive to the chiral selector was crucial to obtain acceptable separations, which is still considered a major limitation of LER-based stationary phases.

\section{Conclusion}

The synthesis, characterization, and chromatographic evaluation of $\mathrm{SC}-2 \mathrm{P}-\mathrm{a}$ new bonded silica stationary phase-were reported in this article. This stationary phase consists of pregabalin as an amino acid ligand linked to the silica surface via triazine attachment. The synthesized material was characterized using FT-IR, UVDRS, and Langmuir adsorption isotherm of MB to define its chemical composition and specific surface area. SC$2 \mathrm{P}$ was susceptible to temperatures higher than $150^{\circ} \mathrm{C}$ but showed good chemical stability when acidic or basic solvent systems were used as mobile phases.

SC-2P was used with copper ions to form in situ LER, which was employed to solve an isomeric mixture of nitrophenol and a racemic mixture of $( \pm)$-ibuprofen using n-hexane:dichloroethane:n-propanol (75:20:5, v/v/v) and dichloroethane:acetonitrile $(90: 10, \mathrm{v} / \mathrm{v})$ as mobile phases, respectively. The separation of the two mixtures was densitometrically confirmed, and $R_{\mathrm{f}}$ and $\alpha$ values were determined. 
The chromatographic characteristics of $\mathrm{SC}-2 \mathrm{P} / \mathrm{Cu}^{2+}$ suggest multiple mechanisms taking place in the separation process. Nevertheless, the formation of solute$\mathrm{Cu}^{2+}$-ligand ternary complexes of different stability constants is proposed to be the major mechanism leading the chiral and isomeric selectivity.

\section{Supplementary information}

Supplementary information accompanies this paper at https://doi.org/10. 1186/s43094-020-00064-8.

Additional file 1: SSA Determination

\section{Abbreviations}

UV-DRS: UV diffuse reflection spectroscopy; MB: Methylene blue; SSA: Specific surface area; C-2P: Cyanuric-2-pregabalin; SC-2P: Silica cyanuric-2-pregabalin; LER: Ligand exchange reagents

\section{Acknowledgements}

Not applicable.

\section{Authors' contributions}

MAR did the experiments, put the characterization protocols, and wrote the manuscript. AA put the protocols for the organic synthesis and contributed to the experiments. AAS supervised the project in all stages, contributed to the interpretation of data, and revised the manuscript. All authors read and approved the final manuscript.

\section{Funding}

This research did not receive any specific grant from funding agencies in the public, commercial, or not-for-profit sectors.

\section{Availability of data and materials}

Data and material are available upon request.

\section{Ethics approval and consent to participate}

Not applicable.

\section{Consent for publication}

Not applicable.

\section{Competing interests}

The authors declare that they have no competing interests.

\section{Author details}

'Department of Food \& Analytical Chemistry, Faculty of Pharmacy, University of Aleppo, Aleppo, Syria. ${ }^{2}$ Department of Chemistry, Faculty of Sciences, University of Aleppo, Aleppo, Syria.

Received: 23 June 2020 Accepted: 20 July 2020

Published online: 31 July 2020

\section{References}

1. Vanhaelen M, Vanhaelen-Fastré R (1988) Thin-layer chromatographydensitometry as a powerful method for the standardization of medicinal plant extracts. In: Dallas FAA, Read H, Ruane RJ, Wilson ID (Eds.) Recent advances in thin-layer chromatography. Springer, Boston, MA, pp. 187-200. https://doi.org/10.1007/978-1-4899-2221-2_20.

2. Spangenberg B, Poole CF, Weins C (2010) Theoretical basis of thin layer chromatography (TLC). In: quantitative thin-layer chromatography-a practical survey. Springer, Berlin, Heidelberg. pp. 13-52. https://doi.org/ https://doi.org/10.1007/978-3-642-10729-0_2

3. Bhushan R, Parshad V (1996) Resolution of ( \pm )-ibuprofen using l-arginineimpregnated thin-layer chromatography. J Chromatogr A 721(2):369-372. https://doi.org/https://doi.org/10.1016/0021-9673(95)00772-5.

4. Bhushan R, Thuku Thiongo G (1998) Direct enantioseparation of some $\beta$ adrenergic blocking agents using impregnated thin-layer chromatography. J
Chromatogr B Biomed Sci Appl 708(1-2): 330-334. https://doi.org/https:// doi.org/10.1016/s0378-4347(97)00646-4.

5. Aboul-Enein HY, El-Awady MI, Heard CM (2003) Enantiomeric resolution of some 2-arylpropionic acids using $\mathrm{I}-(-)$-serine-impregnated silica as stationary phase by thin layer chromatography. J Pharm Biomed Anal 32(4-5):10551059. https://doi.org/https://doi.org/10.1016/s0731-7085(03)00208-5.

6. Sajewicz M, Piętka R, Kowalska T (2005) Chiral separations of ibuprofen and propranolol by TLC. A study of the mechanism and thermodynamics of retention. J Liq Chromatogr Relat Technol 28(16):2499-2513. https://doi.org/ https://doi.org/10.1080/10826070500189638.

7. Bhushan R, Agarwal C (2008) Direct resolution of six beta blockers into their enantiomers on silica plates impregnated with L-asp and L-Glu. J Planar Chromatogr -Mod TLC 21(2):129-134. https://doi.org/https://doi.org/10. 1556/JPC.21.2008.2.10.

8. Bhushan R, Tanwar S (2009) Direct TLC resolution of the enantiomers of three $\beta$-blockers by ligand exchange with cu(II)-l-amino acid complex using four different approaches. Chromatographia 70(5-6):1001-1006. https://doi. org/https://doi.org/10.1365/s10337-009-1216-7.

9. Shapovalova EN, Ananieva IA, Majouga AG, Zik NV, Shpigun OA (2009) Use of gold nanoparticles for immobilization of $\mathrm{L}$-cysteine on TLC plates. Mosc Univ Chem Bull 64(3):159-164. https:/doi.org/https//doi.org/10.3103/50027131409030092.

10. Batra S, Singh M, Bhushan R (2014) L-amino acids as chiral selectors for the enantioseparation of ( \pm )-bupropion by ligand exchange thin-layer chromatography using cu(II) complex via four different approaches. J Planar Chromatogr -Mod TLC 27(5):367-371. https://doi.org/https://doi.org/10. 1556/JPC.27.2014.5.7.

11. Singh M, Malik P, Bhushan R (2016). Resolution of enantiomers of (RS)baclofen by ligand-exchange thin-layer chromatography. J Chromatogr Sci 54(5):842-846. https://doi.org/https://doi.org/10.1093/chromsci/bmw014.

12. Witherow L, Spurway TD, Ruane RJ, Wilson ID, Longdon K (1991) Problems and solutions in chiral thin-layer chromatography: a two-phase "Pirkle" modified amino-bonded plate. J Chromatogr A 553:497-501. https://doi. org/https://doi.org/10.1016/S0021-9673(01)88521-6.

13. Bhushan R, Martens J, Wallbaum S, Joshi S, Parshad V (1997) TLC resolution of enantiomers of amino acids and dansyl derivatives using (1R,3R,5R)-2azabicyclo[3,3,0]octan-3-carboxylic acid as impregnating reagent. Biomed Chromatogr 11(5):286-288. https://doi.org/https://doi.org/10.1002/ (SICI) 1099-0801(199709)11:5<286::AID-BMC698>3.0.CO;2-9.

14. Malik P, Bhushan R (2017) Thin layer chromatographic resolution of some $\beta$ adrenolytics and a $\beta 2$-agonist using bovine serum albumin as chiral additive in stationary phase. J Chromatogr Sci 56(1):92-98. https://doi.org/ https://doi.org/10.1093/chromsci/bm×082.

15. Del Bubba M, Checchini L, Lepri L (2012) Thin-layer chromatography enantioseparations on chiral stationary phases: a review. Anal Bioanal Chem 405(2-3):533-554. https://doi.org/https://doi.org/10.1007/s00216-012-6514-5.

16. Taylor CP (2009) Mechanisms of analgesia by gabapentin and pregabalincalcium channel a2- $\delta$ [Cava2- $\delta$ ] ligands. Pain 142(1):13-16. https://doi.org/ https://doi.org/10.1016/j.pain.2008.11.019.

17. Melero JA, Iglesias J, Sáinz-Pardo J, Arsuaga JM (2007) Synthesis of titanium containing periodic mesoporous organosilica, Stud Surf Sci Catal 170:450455. https://doi.org/https://doi.org/10.1016/S0167-2991(07)80875-5.

18. Fang QR, Yuan DQ, Sculley J, Lu WG, Zhou HC (2012) A novel MOF with mesoporous cages for kinetic trapping of hydrogen. Chem Commun 48(2): 254-256. https://doi.org/https://doi.org/10.1039/C1CC15687J.

19. Maity N, Barman S, Abou-Hamad E, D'Elia V, Basset JM (2018) Clean chlorination of silica surfaces by a single-site substitution approach. Dalton Trans 47(12):4301-4306. https://doi.org/https://doi.org/10.1039/C8DT00186C.

20. Jork H, Funk W, Fischer W, Wimmer H (1990) Thin-layer chromatography reagents and detection methods (Volume 1a). English edition: Hampson F, Hampson JA, VCH Verlagsgesellschaft rabH, Weinheim, Germany.

21. Itodo AU, Itodo HU, Gafar MK (2010) Estimation of specific surface area using Langmuir isotherm method. J Appl Sci Environ Manage 14(4):141145. https://doi.org/https://doi.org/10.4314/jasem.v14i4.63287.

22. Rager T, Geoffroy A, Hilfiker R, Storey JMD (2012) The crystalline state of methylene blue: a zoo of hydrates. Phys Chem Chem Phys 14(22):80748082. https://doi.org/https://doi.org/10.1039/C2CP40128B

23. Schuster G, Lindner W (2011) Chocolate HILIC phases: development and characterization of novel saccharide-based stationary phases by applying non-enzymatic browning (Maillard reaction) on amino-modified silica surfaces. Anal Bioanal Chem 400(8):2539-2554. https://doi.org/https://doi. org/10.1007/s00216-011-4745-5. 
24. Coates J (2000) Interpretation of infrared spectra: a practical approach. In: Meyers RA (Ed.), Encyclopedia of analytical chemistry. John Wiley and Sons Ltd., New York, pp. 10815-10837. https://doi.org/https://doi.org/10.1002/ 9780470027318.a5606.

25. Launer PJ (2013) Infrared analysis of organosilicon compounds: spectrastructure correlations. In: Arkles B, Larson GL (eds) Silicon compounds: silanes and silicones, a survey of properties and chemistry, 3rd edn. Gelest Inc., Morrisville, PA, USA, pp 177-180

26. Boddu V, Kim S, Adkins J, Weimer E, Paul T, Damavarapu R (2017) Sensitive determination of nitrophenol isomers by reverse-phase high-performance liquid chromatography in conjunction with liquid-liquid extraction. Int J Environ Anal Chem 97(11):1053-1064. https://doi.org/10.1080/03067319. 2017.1381235

27. Ji XN, Ai SS, Tang J, Qu H, Bian DJ (2015) Determination of nitrophenol isomers in water. Adv Mater Res 1083:80-83. https://doi.org/10.4028/www. scientific.net/amr.1083.80

\section{Publisher's Note}

Springer Nature remains neutral with regard to jurisdictional claims in published maps and institutional affiliations.

\section{Submit your manuscript to a SpringerOpen ${ }^{\circ}$ journal and benefit from:}

- Convenient online submission

- Rigorous peer review

- Open access: articles freely available online

- High visibility within the field

- Retaining the copyright to your article

Submit your next manuscript at $\boldsymbol{\wedge}$ springeropen.com 